\title{
Development and Calibration of Automated Multiple-Ring Infiltrometer
}

\author{
Olotu Y., Rodiya, Evboifo N.O.
}

\begin{abstract}
An automatic triple-ring infiltrometer was developed using a set of pre-set sensors and transducer (AP 403, AP 404, $A P 405$ and $A P$ 406, RAP001 and RAP002). The aluminum probe sensors were graduated and arranged in series to monitor the rate at which water is infiltrating into the soil layer. The working principle of automatic triple-ring infiltrometer was developed using six probes with depth calibration of $1.0 \mathrm{~mm}, 26.7$ $\mathrm{mm}, 12.4 \mathrm{~mm}$, and $12.7 \mathrm{~mm}$, respectively. The result obtained showed strong agreement with a coefficient of determination $\boldsymbol{R}^{2}=$ 0.963 , indicating positive proportionality between cumulative infiltration and time taken for the water to infiltrate at different depths. The instrument has a measuring accuracy of $\pm 0.3 \mathrm{~mm}$ infiltration depth. The device works effectively under biochar amended soil and other soil formations with high precision. Accurate infiltration data generated by the instrument would be applied to estimate the depth of water available to plant and predict possible agricultural drought.
\end{abstract}

Keywords: Triple-Ring Infiltrometer, Probe Sensor, Soil Layer, Calibration, Accuracy

\section{INTRODUCTION}

Infiltration is significant hydrologic to the hydrologic cycle (Mishra et al., 2003). Water that falls as precipitation runs over land, eventually reaching streams, lakes, rivers, and oceans or infiltrate through the soil surface into the soil profile (Bouwer, 1986; Cuenca, 1989). Rainwater that runs off overland causes erosion, flooding, and water quality degradation (Dixon, 1975). On the other hand, infiltration forms the significant process of soil moisture to sustain vegetation's growth and filtered through soil mass to remove contaminants in form of physical, chemical, and biological processes. It replenishes the groundwater supply to wells, springs, and streams (Gana, 2011; Mishra et al., 2003). Infiltration is significant to live on land on our planet. The ability to quantify infiltration is of great importance in watershed management. Prediction of flooding, erosion, and pollutant transport depends on the runoff rate, which is directly affected by the infiltration rate. In developing integrated hydrologic models, accurate methods for characterizing infiltration are required (Gana, 2011; Oku and Aiyelari, 2011).

Manuscript received on 25 April 2021 | Revised Manuscript received on 28 April 2021 | Manuscript Accepted on 15 May 2021 | Manuscript published on 30 May 2021

* Correspondence Author

Olotu Y*., Department of Agricultural \& Bio-Environmental Engineering, Auchi Polytechnic, Auchi, Nigeria

Rodiya*, Department of Agricultural \& Bio-Envi. Engineering, The Federal Polytechnic, Ado-Ekiti, Nigeria. Email: realyahaya@yahoo.com Evboifo N.O., Department of Agricultural Technology, Auchi Polytechnic, Auchi, Nigeria

(c) The Authors. Published by Lattice Science Publication (LSP). This is an open access article under the CC-BY-NC-ND license (http://creativecommons.org/licenses/by-nc-nd/4.0/)
The rate at which water enters into the soil layer per given time is normally measured using single or multiple rings infiltrometers. The device consists of concentric cylindrical rings which are gently driven into the soil at a preset depth. The installed rings are filled up with water and entering into the soil mass is measured against time. Because of the soil's capillary forces and layers of reduced hydraulic conductivity at the soil's lower levels, water does not flow purely vertically beneath the cylinder (Haggard et al., 2005). Infiltration has received several attentions from the soil and water scientists/engineers because of the fundamental role of infiltration characteristics in land-surface and subsurface hydrology, irrigation, and agriculture. Water infiltration into soil is a function of soils' physical properties, primarily the initial soil water content and saturated hydraulic conductivity, soil structure and texture, vegetation, and plant root density (Lili et al., 2008). Direct measurement and empirically-based mathematical models can be applied to estimate soil infiltration behavior and characteristics (Oku and Aiyelari, 2011).

Infiltration is an essential variable for designing hydraulic structures. Therefore, this study is focused on developing an automated tripe-ring infiltrometer that is expected to produce a realistic and accurate infiltration rate on different soil types. This result will be useful in formulating and running hydrological models. The triplering infiltrometer is not commonly used for directly measuring infiltration rates. It consists of three concentric rings of various preset diameters. Infiltration rate is determined using the surface area, amount of water infiltrated per unit as developed within the automated instrument.

\section{MATERIALS AND METHODS}

\section{Construction of triple rings infiltrometer}

The mechanical operated triple-rings infiltrometer (TRI) consists of three main parts: the infiltration module (three concentric rings), driving disc, suspended weighing support. Other accessories are calibrated infiltration tank, $20 \mathrm{~mm}$ diameter, and $1.0 \mathrm{~m}$ length of connecting host. The parts of the instrument are detachable in order to ensure portability. The rings were constructed with a $2 \mathrm{~mm}$ metal sheet, as shown in Table 1 .

Table 1: The specifications of the rings

\begin{tabular}{|c|c|c|c|}
\hline Rings & Diameter $(\mathrm{mm})$ & Height $(\mathrm{mm})$ & $\begin{array}{l}\text { Gauge size } \\
(\mathrm{mm})\end{array}$ \\
\hline A & 600.0 & 400.0 & 2.0 \\
\hline B & 400.0 & 400.0 & 2.0 \\
\hline C & 200.0 & 400.0 & 2.0 \\
\hline
\end{tabular}




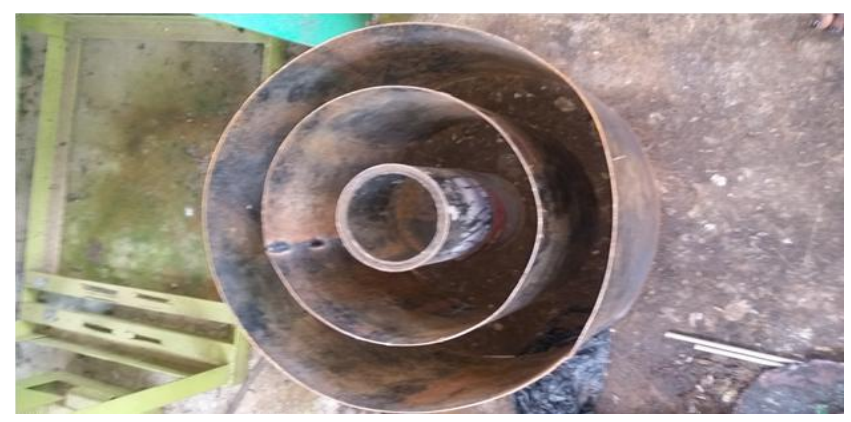

Plate 1: Arrangement of concentric rings (A-B-C)
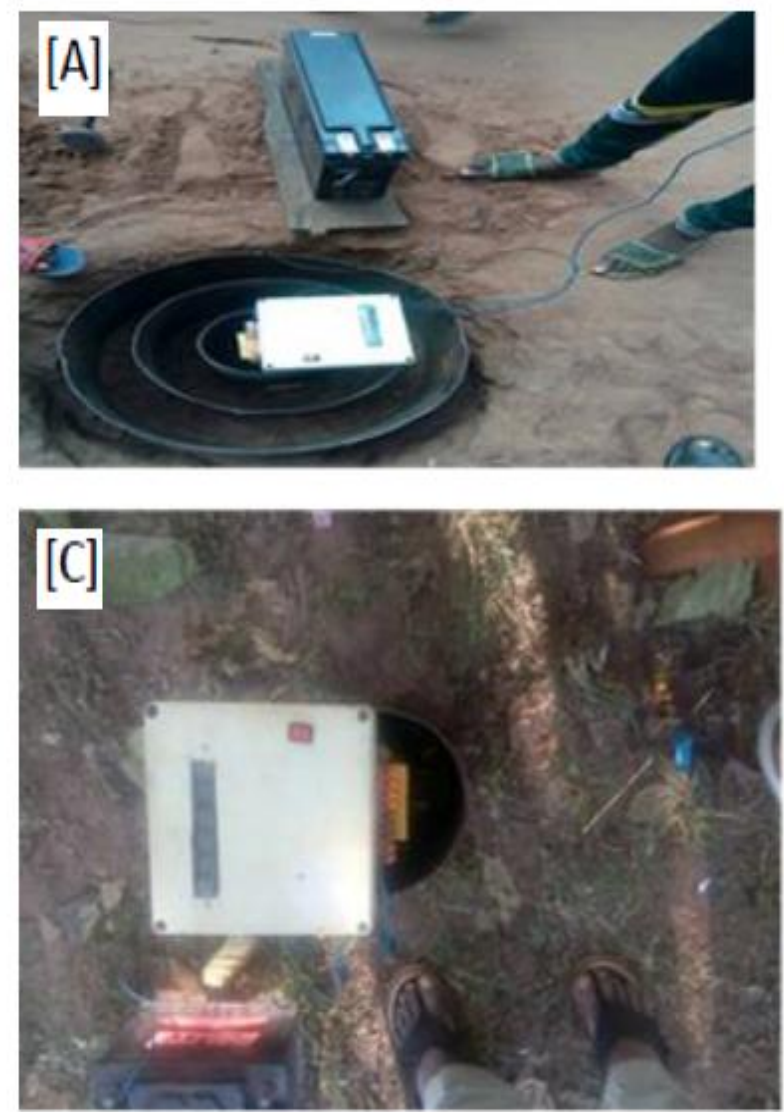

The infiltrometer consists of three concentric metal rings (see plate 1), which are driven into the soil with the aid of driving plate. Plate $2 \mathrm{a}, \mathrm{b}, \mathrm{c}$ and $\mathrm{d}$ show the completed automatic triple infiltrometer during calibration processes.

Plate 2: Calibration of triple ring infiltrometer

\section{Calibration of triple-ring infiltrometer}

The automatic triple ring infiltrometer uses an analog sensor consisting of six sensitive probes of different lengths (enament aluminum). The probes have direct contact with water. When a probe (sensor), i.e., enament aluminum, touches the liquid, it converts the physical variable (water) to the electrical variable as described by Mbagwu (1995) and Prieksat et al. (1992). The calibrated values range from 1 to 7 , and each of the values represents each sensing probe. In this same work, the electrical refers to a change in resistance, i.e., from $100 \mathrm{k} \Omega$ to infinity $(\mathrm{Ohm})$, which is used to activate the control line of the display unit. As the respective probes (sensor, i.e., enament aluminum) touch the liquid (water), all the calibrated values are on (Ogbe et al., 2008; Okai et al., 2000). Once the water has infiltrated below any of the sensors, the light is off. The process is continuous when the probe's tip (sensor or enament aluminum) gets disengaged from the physical variable. The control unit sends a signal to the physical variable (water). The display unit is made up of a light-emitting diode $(5 \mathrm{v}$ 65 mini amp). The sensor is a metallic conductor that is
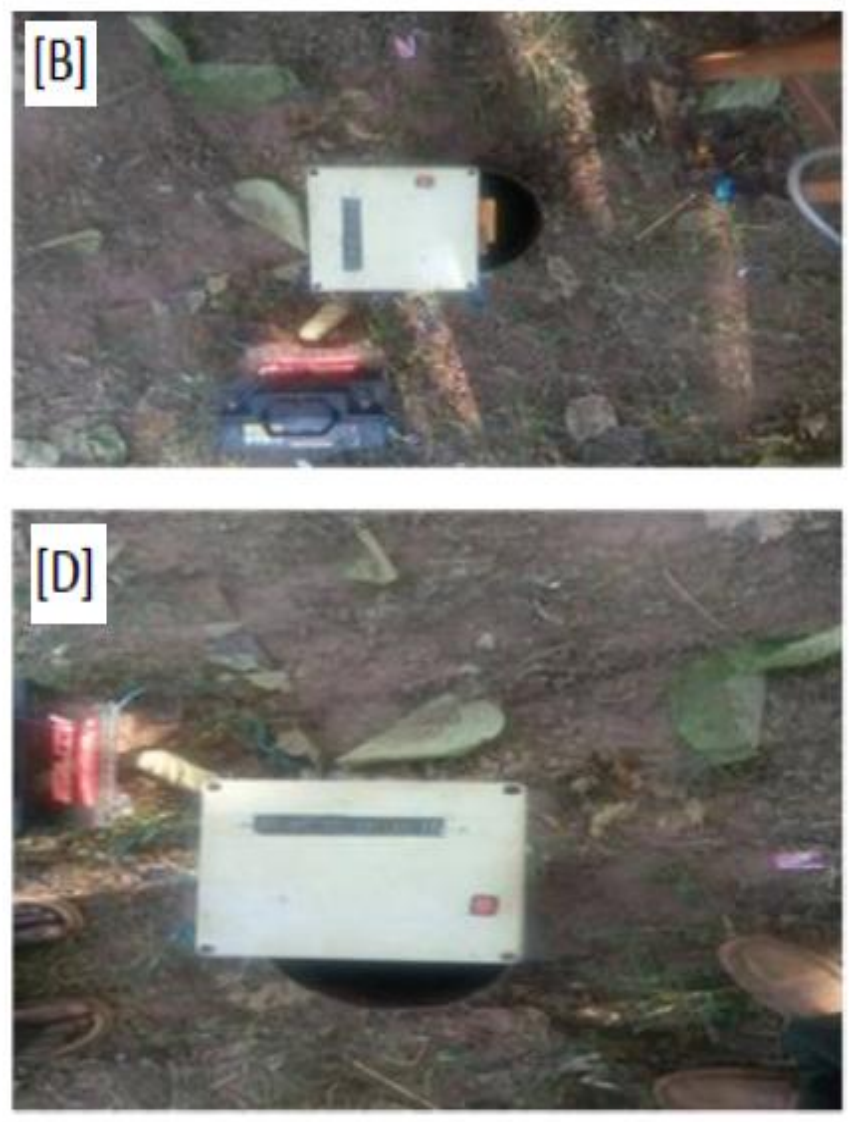

specifically chosen to not corrode due to emanate aluminated conductor.

The sensors are made of six different probe lengths of AP 403(280mm); AP 404 (258.0 mm); AP 405 (237.0 mm); AP 406 (215.0 mm); RAP001 (198.0 mm) and RAP002 $(177.0 \mathrm{~mm})$ respectively. However, RAP001 and RAP002 are reference sensors. The selected sensors' difference referenced to the inner ring (C) is $120.0 \mathrm{~mm}, 142.0 \mathrm{~mm}$, $163.0 \mathrm{~mm}, 185.0 \mathrm{~mm}, 202.0 \mathrm{~mm}$, and $223.0 \mathrm{~mm}$. The corresponding infiltration water volume is $0.00 l, 0.84 l$, $0.39 l, 0.40 l, 0.52 l$ and $0.55 l$.

\section{Data collection and analysis}

Developed automated triple-ring infiltrometer was tested on bare and cropped soil to measure infiltration rates. Generated data were subjected to statistical analysis using sigmal plot 1.0 and SSPS software package.

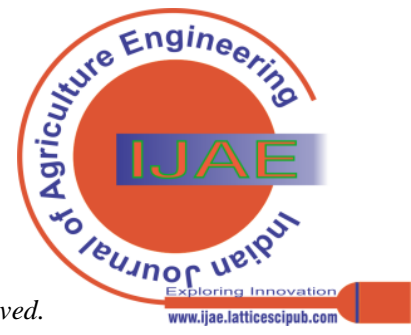




\section{RESULTS AND DISCUSSION}

Developed automatic triple ring infiltrometer was calibrated and used to measure infiltration rates on bare and cropped soils (Clay and Sand) as in agreement several studies (Runbin et al., 2011; Skaggs and Khaleel, 1982). The measured infiltration rates are in Tables 2-6. Plate 2 shows the instrument during operation. The aluminum probe sensor (AP403) indicates the initial infiltration reading, which is $0.0 \mathrm{~mm}$ for all the sensors. The final infiltration readings against various time intervals are shown in Tables 2-6.

Table 2: Calibration of automatic triple Ring-Infiltrometer

\begin{tabular}{|c|c|c|c|c|c|c|}
\hline Sensor Pos. & Sensor code & $\mathrm{I}(\mathrm{l})$ & $\mathrm{I}(\mathrm{mm})$ & $\mathrm{CI}(\mathrm{mm})$ & Time $(\mathrm{mins})$ & $\mathrm{CIR}(\mathrm{mm} / \mathrm{min}$ \\
\hline 6 & AP403 & 0.00 & 0.00 & 0.00 & 0.00 & 0.00 \\
\hline 5 & AP404 & 0.84 & 26.70 & 26.70 & 6.80 & 3.90 \\
\hline 4 & AP405 & 0.39 & 12.40 & 39.10 & 20.40 & 1.90 \\
\hline 3 & AP406 & 0.40 & 12.70 & 51.80 & 28.50 & 1.80 \\
\hline 2 & RAP001 & 0.52 & 16.50 & 68.30 & 39.20 & 1.70 \\
\hline 1 & RAP002 & 0.55 & 17.50 & 85.80 & 56.20 & 1.50 \\
\hline
\end{tabular}

Table 3: Infiltration result from Triple Infiltrometer using on cropped sand soil

\begin{tabular}{|c|c|c|c|c|c|}
\hline Sensor Pos. & Sensor code & $\mathrm{I}(\mathrm{mm})$ & $\mathrm{CI}(\mathrm{mm})$ & Time $(\mathrm{mins})$ & $\mathrm{CIR}(\mathrm{mm} / \mathrm{min})$ \\
\hline 6 & AP403 & 0.00 & 0.00 & 0.00 & 0.00 \\
\hline 5 & AP404 & 38.40 & 38.40 & 4.90 & 7.80 \\
\hline 4 & AP405 & 20.30 & 58.70 & 15.60 & 3.80 \\
\hline 3 & AP406 & 15.20 & 73.90 & 25.60 & 2.90 \\
\hline 2 & RAP001 & 22.10 & 96.00 & 33.60 & 2.80 \\
\hline 1 & RAP002 & 15.60 & 111.60 & 40.60 & 2.70 \\
\hline
\end{tabular}

Table 4: Infiltration result from Triple Infiltrometer on bare sand soil

\begin{tabular}{|c|c|c|c|c|c|}
\hline Sensor range & Sensor code & $\mathrm{I}(\mathrm{mm})$ & $\mathrm{CI}(\mathrm{mm})$ & Time $(\mathrm{mins})$ & $\mathrm{CIR}(\mathrm{mm} / \mathrm{min})$ \\
\hline 6 & AP403 & 0.00 & 0.00 & 0.00 & 0.00 \\
\hline 5 & AP404 & 60.10 & 60.10 & 3.20 & 18.80 \\
\hline 4 & AP405 & 47.90 & 108.0 & 10.10 & 10.70 \\
\hline 3 & AP406 & 33.10 & 141.1 & 18.20 & 7.80 \\
\hline 2 & RAP001 & 20.90 & 162.0 & 24.00 & 6.75 \\
\hline 1 & RAP002 & 18.00 & 180.0 & 30.20 & 5.96 \\
\hline
\end{tabular}

Table 5: Infiltration result from Triple Infiltrometer on bare clay soil

\begin{tabular}{|c|c|c|c|c|c|}
\hline Sensor range & Sensor code & I $(\mathrm{mm})$ & CI $(\mathrm{mm})$ & Time $(\mathrm{mins})$ & CIR(mm/min) \\
\hline 6 & AP403 & 0.00 & 0.00 & 0.00 & 0.00 \\
\hline 5 & AP404 & 15.30 & 15.30 & 10.60 & 1.40 \\
\hline 4 & AP405 & 10.20 & 25.50 & 26.90 & 0.94 \\
\hline 3 & AP406 & 7.10 & 32.60 & 43.90 & 0.74 \\
\hline 2 & RAP001 & 4.30 & 36.90 & 64.60 & 0.57 \\
\hline 1 & RAP002 & 4.00 & 40.90 & 79.60 & 0.51 \\
\hline
\end{tabular}

Table 6: Infiltration result from Triple Infiltrometer on cropped clay soil

\begin{tabular}{|c|c|c|c|c|c|}
\hline Sensor range & Sensor code & $I(\mathrm{~mm})$ & $\mathrm{CI}(\mathrm{mm})$ & Time $(\mathrm{mins})$ & $\mathrm{CIR}(\mathrm{mm} / \mathrm{min})$ \\
\hline 6 & AP403 & 0.00 & 0.00 & 0.00 & 0.00 \\
\hline 5 & AP404 & 8.90 & 8.90 & 15.40 & 0.60 \\
\hline 4 & AP405 & 6.70 & 15.80 & 30.30 & 0.52 \\
\hline 3 & AP406 & 4.10 & 19.90 & 61.30 & 0.32 \\
\hline 2 & RAP001 & 3.10 & 23.00 & 75.70 & 0.30 \\
\hline 1 & RAP002 & 2.50 & 25.50 & 100.90 & 0.25 \\
\hline
\end{tabular}


The concept of automatic triple-ring infiltrometer was arranged with six aluminum probe sensors in series corresponding to various infiltration depths. The infiltration depth recorded by each sensor was monitored with an automatic stop-watch. Fig.4.1 shows the output of equipment calibration using different statistics validations. Strong agreement was obtained with a coefficient of determination $\mathrm{R}^{2}=0.963$, indicating positive proportionality between cumulative infiltration and time taken for the water to infiltrate at different depths. The result agrees with findings from the studies of Ankeny et al. (1988) and Constantz and Murphy (1987). Therefore, the accuracy of automatic triple-ring was evaluated at $\pm 3 \mathrm{~mm}$ infiltration depth. The instrument is susceptible to infiltration rates on different soil types and the nature of the soil surface, texture, and structure (Mahdian and Gallichand, 1995; Ellen, 2006). The computed infiltration rate was highest with 18.8 $\mathrm{mm} / \mathrm{min}$ for AP 404 under the bare sandy soil. This value corresponds to $7.80 \mathrm{~mm} / \mathrm{min}$ for cropped sandy soil (Tables 3-6). Infiltration rates of $1.40 \mathrm{~mm} / \mathrm{min}$ and $0.60 \mathrm{~mm} / \mathrm{min}$ correspond to AP 404 bare and cropped clay soil, respectively. Overall simulation results showed that higher infiltration rates were produced from the sandy soil. This is due to the loose soil particle that allows water movement into the soil mass layer.

Statistics metrics in Figs. 2-5 show the relationship between infiltration rates CIR $(\mathrm{mm} / \mathrm{min})$. The time is taken (minutes) for both soils under cropped and bare soil conditions. The coefficient of determination $\left(\mathrm{R}^{2}\right)$ for cumulative infiltration rate and time has higher in cropped soil than the bare soil, with $\mathrm{R}^{2}$ values of 0.945 and 0.737 for cropped sandy and clay soils. However, the values for bare sandy and clay soil are 0.890 and 0.724 . It is deduced that the instrument performs better on cropped soil that the bare soil.

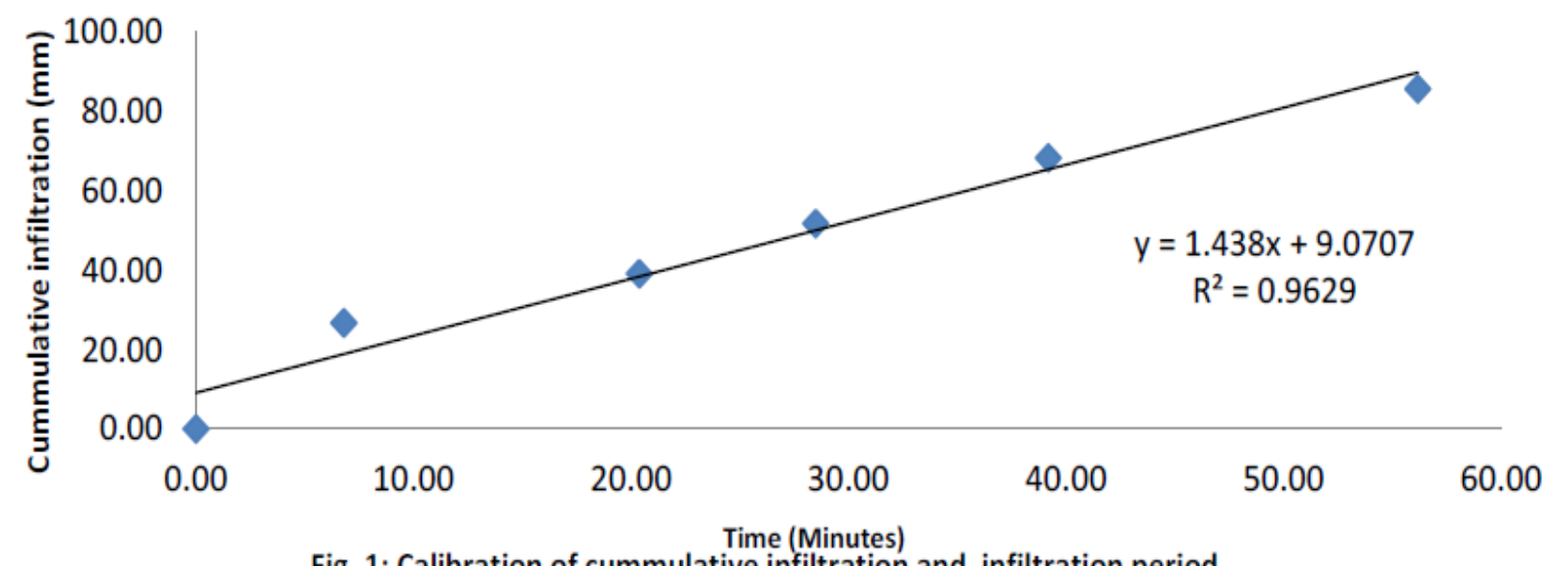

Fig. 1: Calibration of cummulative infiltration and infiltration period
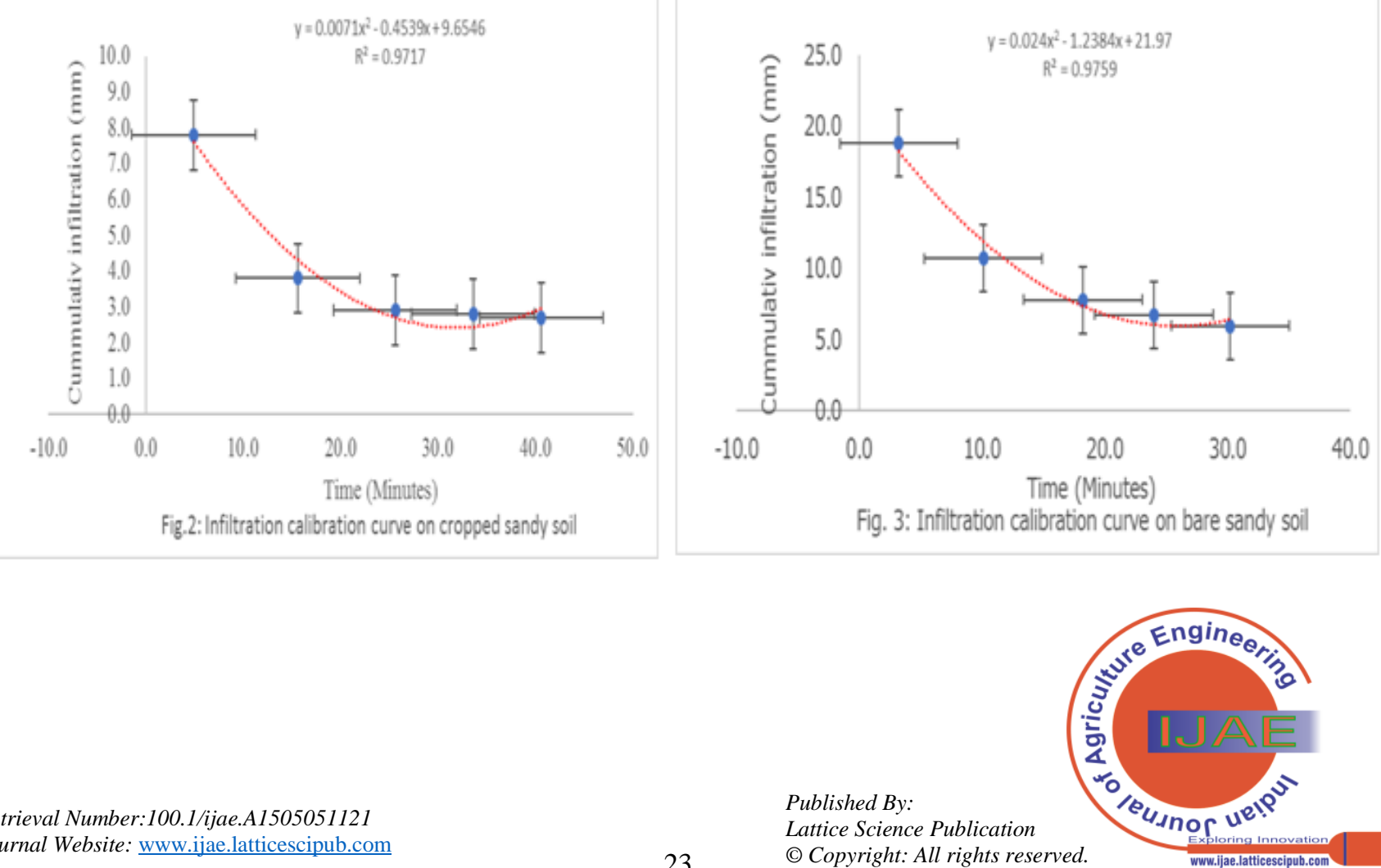


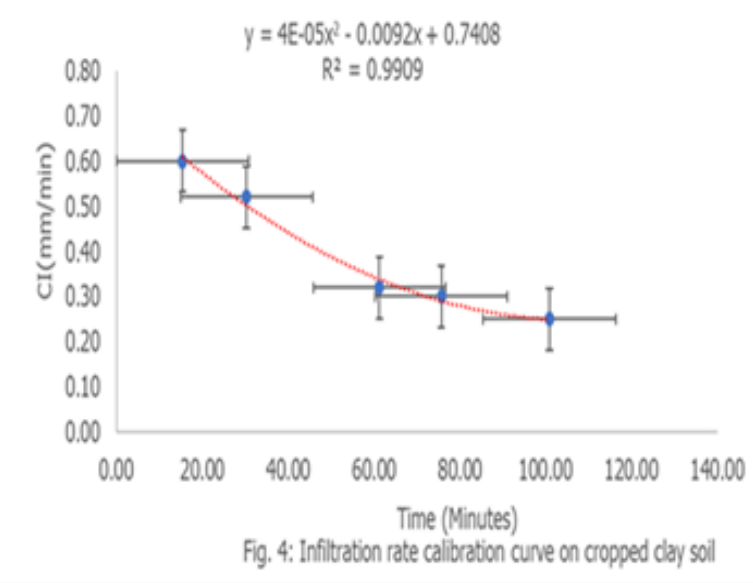

IV. CONCLUSION

Measurement of infiltration rate using a convectional infiltrometer is time-consuming, and most instances produce approximated results. The developed instrument automatically records infiltration depths with the aid of serially arranged aluminum probe sensors, which relay the signal from the probe to the mounted display. The instrument has a measuring accuracy of $\pm 3 \mathrm{~mm}$ infiltration depth. Aluminum probe sensor (AP 403) records the initial infiltration reading while AP 404, AP 405, and AP 406 record the final infiltration readings at different depths. Overall outputs show that the soil condition has effects on infiltration rate. The calibration of infiltration against time revealed that a high value of infiltration was obtained at the beginning of the simulation and decreased with a constant infiltration rate. The soil's infiltration capacity is almost zero (saturated soil). Accurate infiltration data generated by the instrument would be applied to estimate the depth of water available to plant and predict possible agricultural drought.

\section{REFERENCES}

1. Bouwer, H. (1986). Intake rate: cylinder infiltrometer. Pp. 825-844 in Klute A (Ed.). Methods of Soil Analysis, Part 1: Physical and Mineralogical Methods, 2nd Ed. Madison: American Society of Agronomy and Soil Science Society of America. 1188 p. ISBN 089118-088-5.

2. Cuenca, R. H. (1989). Irrigation System Design - An Engineering Approach. Prentice-Hall, Inc., Englewood Cliffs, NJ. 552 pp.

3. Dixon, R.M.(1975). Design and use of closed-top infiltrometers. Soil Sci. Soc. Am. Proceedings, 39, 755-763. [CrossRef]

4. Ellen, T. (2006). Comparison of infiltration equations and their field validation by rainfall simulation. M.Sc. Thesis Submitted to the Faculty of the Graduate School of The University of Maryland.

5. Gana, A. K. (2011). Cow dung: soil amendment agent for the sandy upland sugarcane ecology in Nigeria. Journal of Agricultural Technology 2011 Vol. 7(2): 497-505

6. Haggard, B. E., Moore P. A. and Jrand K. R. (2005). Effect of Slope on Runoff from a Small Variable-Slope Box. Journal of Environmental Hydrology. 13 (2). pp 25-45. Available: http://hydroweb.com.

7. Lili, M., Bralts, V. F., Yinghua, P., Han, L. and Tingwu, L. (2008) Methods for measuring soil infiltration. State of the art, Int. J.Agric\&Biol Eng. 1(1), 22-30.

8. Mbagwu, J. S. C. (1995). Testing the goodness of fit of infiltration models for highly permeable soils under different tropical soil management systems. Soil \& Tillage Research 34: 199-205. [CrossRef]

9. Mishra, S. K., Tyagiand, J. V. and Singh, V. P. (2003). Comparison of infiltration models. Journal of Hydrological Processes. 17: $2629-$ 2652. [CrossRef]

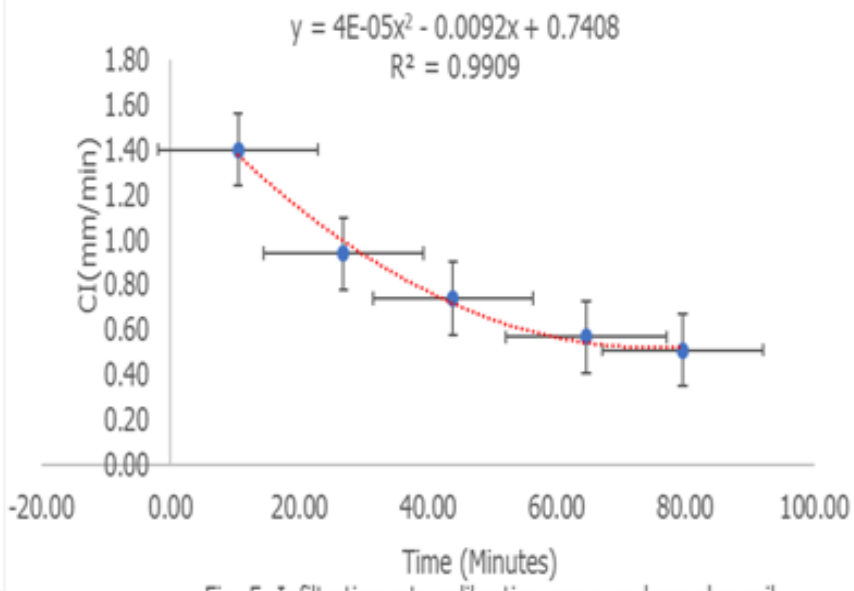

Fig. 5: Infiltration rate calibration curve on bare clay soil

10. Ogbe, V. B., Mudiare, O. J. and Oyebode, M. A. (2008). Evaluation of Furrow irrigation water advance models. Journal of Agricultural Engineering and Technology (JAET), Volume 16 (NO. 1) pg. $74-83$.

11. Okai, I. A., Ramalan, A. A. and Adeoye, K.B. (2000). Infiltration characteristics of soils as relate to other soil physical properties of a soil subgroup in Kadawa Research Station of Nigeria. Nig. J. Soil Res. 1: 8-11.

12. Oku, E. and Aiyelari, A. (2011). Predictability of Philip and Kostiakov infiltration model under inceptisols in the Humid Forest Zone, Nigeria. Kasetsart Journal (Natural Science), 45: 594 -602.

13. Oku, E. and Aiyelari, A. (2011). Predictability of Philip and Kostiakov infiltration model under inceptisols in the Humid Forest Zone, Nigeria. Kasetsart Journal (Natural Science), 45: 594 -602.

14. Runbin, D., Clifford, B. F. and John, B. (2011). Field evaluation of infiltration models in lawn soils. Irrigation Sci (2011) 29:379389 [CrossRef]

15. Skaggs, R. W., and Khaleel, R. (1982) Chapter 4: Infiltration. In Hydrologic modelling of Small Watersheds. St Joseph, Mich.: ASAE.

16. Ankeny, M. D., Kaspar, T. C., and Horton, R. (1988). Design for an automated tension infiltrometer. Soil Science Society of America Journal 52, 893-6. [CrossRef]

17. Constantz, J., and Murphy, F. (1987). An automated technique for flow measurements from Mariotte reservoirs. Soil Science Society of America Journal 51, 252-4. [CrossRef]

18. Prieksat, M. A., Ankeny, M. D., and Kaspar, T. C. (1992). Design for an automated, self-regulating infiltrometer. Soil Science Society of America Journal 56, 1409-11. [CrossRef]

19. Mahdian, M. H. and Gallichand, J. (1995). Validation of the SUBTOR model for simulating soil water content. Transaction of the ASAE Vol 38(2):513 - 520. [CrossRef] 